Research Article

\title{
Investigating the Factors Associated with the Level of Expression of Estrogen and Progesterone Receptors in Patients Suffering from Colorectal Cancer
}

\author{
Saleheh Salehi far, ${ }^{1}$ Maryam Soltani, ${ }^{2}$ Mahmoud Zardast, ${ }^{3}$ \\ and Mohammad Reza Ghasemian Moghaddam (iD ${ }^{4,5}$ \\ ${ }^{1}$ Student Research Committee, Birjand University of Medical Sciences, Birjand, Iran \\ ${ }^{2}$ Clinical Research Development Unit of Razi Hospital, Birjand University of Medical Sciences, Birjand, Iran \\ ${ }^{3}$ Department of Pathology, School of Medicine, Cardiovascular Diseases Research Center, Birjand University of Medical Sciences, \\ Birjand, Iran \\ ${ }^{4}$ Department of Surgery, School of Medicine, Cardiovascular Diseases Research Center, Birjand University of Medical Sciences, \\ Birjand, Iran \\ ${ }^{5}$ Clinical Research Development Unit of Imam Reza Hospital, Birjand University of Medical Sciences, Birjand, Iran
}

Correspondence should be addressed to Mohammad Reza Ghasemian Moghaddam; dr.ghasemian54@gmail.com

Received 14 July 2021; Accepted 20 September 2021; Published 15 October 2021

Academic Editor: Samuel Antwi

Copyright (C) 2021 Saleheh Salehi far et al. This is an open access article distributed under the Creative Commons Attribution License, which permits unrestricted use, distribution, and reproduction in any medium, provided the original work is properly cited.

\begin{abstract}
Background. The present study was performed to investigate the factors related to the expression level of estrogen and progesterone receptor in patients with colorectal cancer. Material and Methods. This crosssectional study was performed on 54 patients suffering from colorectal cancer referring to Imam Reza Hospital in Birjand during 2018-2019. After the biopsy performed during surgery, the specimen was sent for immunohistochemistry, and the status of receptors was determined. Eventually, the data were analyzed by SPSS 22. Results. Out of the 54 patients studied, $64.8 \%$ were male. The mean age of the patients was $62.28 \pm 14.03$ years. The level of expression of beta-estrogen receptors and progesterone receptors had a significant relationship with age, consuming drugs of abuse, and familial history $(P=0.001)$. Also, the level of expression of estrogen and progesterone receptors of patients with a more advanced stage of cancer was significantly lower $(P=0.001)$. Conclusion. The extent of expression of estrogen and progesterone receptors affects the progression and prognosis of disease. Thus, through hormone therapy, a step can be taken to reduce the progression and even to treat colorectal cancer.
\end{abstract}

\section{Introduction}

1.1. Epidemiology Of Colorectal Cancer. Cancer is one of the important health plights and the third cause of mortality worldwide. Colorectal cancer is the third common cancer globally, claiming $10 \%$ of cancer mortality [1]. Universally, most cases of colorectal cancer occur in industrial countries, though in less-developed countries because of adopting the Western lifestyle, its prevalence is progressively increasing [2]. Research has shown that over the past 10 years, mortality because of colorectal cancer has grown in Asia. Japan has the highest rate of incidence of colorectal cancer especially in men, but since it is one of the first countries in implementing the screening program in year, the rate of mortality is lower in this country compared to Europe $[1,3]$. In Iran, the standard incidence of this cancer has been reported 7 cases per every 100,000 persons, and it is the fourth common cancer. This cancer with mortality rate of 1.90 per 100,000 comprises about $13 \%$ of mortalities resulting from digestive system cancers and $5.3 \%$ of nonaccidental mortality causes in Iran [4]. The 
mortality caused by colorectal cancer is increasing in Iran, whereby there is a direct relationship between older age and mortality of this cancer [5].

1.2. The Level of Expression of Estrogen and Progesterone Receptors. Since the formation of women's health initiative in 1991 and based on several epidemiological studies, the ovarian steroids have been considered to be protective against cancer. Different studies in animal models show low risk of developing cancer in the presence of estrogens. Nevertheless, some studies show that once the disease develops, estrogens inhibit cellular proliferation, while some others indicate that they induce mitogenic effects. The oncogenic effects of estrogens have been widely examined in breast and ovarian cancer, but its function in colorectal cancer is poorly understood. Concerning the receptors, it has been found that beta-estrogen receptor is the dominant isoform in the colon, and its expression is lost during progression of colon cancer. This suggests that these can have a very significant role in progression of this disease. Recent studies on the tumor specimens of affected patients have indicated that overexpression is associated with better prognosis, and they support its role as a possible target for prevention from chemotherapy. The alpha-estrogen receptor expression is minimum in colon cells as well as in colon cancer cells. Thus, most studies show that the protective effects of estradiol in the colon cancer are undertaken by beta type [6]. In addition to the established effects of estrogens on colon tumorigenesis, progesterone (P4) has also been known as another ovarian steroid involved in this disease. Some studies have reported no expression of progesterone receptor (PR) in colon tumors. In addition, some studies have proposed artificial progestins as factors preventing colon cancer [7].

1.3. The Aim Of Study. Considering the importance of expression of estrogen and progesterone hormones with this disease, the present study was conducted to examine the factors associated with the level of expression of estrogen and progesterone receptors in patients suffering from colorectal cancer.

\section{Material and Methods}

2.1. Study Design and Setting. In this crosssectional study, all individuals who had colorectal cancer based on clinical symptoms as well as histopathology and underwent surgery plus colon resection in Imam Reza Hospital in Birjand from 5 April 2018 to 20 September 2019 were included. After acquiring ethics code from Birjand University of Medical Sciences (Ethics code: Ir.bums.Rec.1397.257) and receiving written informed consent form from the patients, demographic variables including age, gender, using opium, cigarette, hookah, and alcohol, history of urethrosigmoidostomy, familial history of colorectal cancer, history of having inflammatory bowel diseases, and colorectal cancer localization were completed based on a predesigned checklist.

The biopsy specimen taken during surgery was sent for immunohistochemistry, whereby the positivity or negativity as well as grade of receptors in the tissue were evaluated. Briefly, first primary slides and histological specimens were prepared as paraffin blocks in pathology center of Imam Reza Hospital in Birjand from the cancerous operated tissue and then assessed by a pathologist. Next, proper blocks and specimens were chosen for IHC staining, whereby some cuts were given with microtome from the relevant blocks and then transferred onto salinized slides for IHC staining. The specimens that did not have suitable target tissue in the reexamination were excluded from the study. Immunohistochemistry is a process for locating proteins in the cells of a tissue. In this method, using monoclonal antibodies, cell antigens are identified. In this plan, ER and PR markers on the colorectal cancer specimens were evaluated as follows: preparing a slide smeared with poly-L-lysine adhesive (which was already available and used accordingly), preparing 5-6 micron thin cuts of paraffin block, placing the slides for $15-20 \mathrm{~min}$ in $60^{\circ} \mathrm{C}$ autoclave for deparaffination, passing a basket containing the slides from four xylol containers for $30 \mathrm{~min}$, passing basket containing slides from four alcohol containers $70,80,90$, and 100 , washing with distilled water ( 5 clean distilled water containers), placing the basket in microwave oven E7 at $95-98^{\circ} \mathrm{C}$ with $10 \mathrm{X}$ retrieval antigen solution in order to withdraw and sensitize the cell wall for 30-45 min, washing the basket of slides in two clean tested water containers, dragging Daku pen or a pen smeared with Vaseline in the specimens to fade the markers and solutions, pouring oxygenated water $3 \%$ on slides in a moist environment for $30 \mathrm{~min}$, washing with clean distilled water, pouring primary antibody ER and PR as a drop on the slides in a moist and preferably rather warm environment for better reaction for $90 \mathrm{~min}$, washing with clean distilled water, pouring secondary antibody HRP enhancer as one drop on the slides in a moist medium and preferably warm for better reaction for $30 \mathrm{~min}$, washing with clean distilled water, pouring the next antibody poly vie plus mouse/rabbit HRP label (Biosystem) as one drop on the slides in a moist and preferably warm medium for better reaction for $30 \mathrm{~min}$, washing with clean distilled water, pouring DAN chromogen (Biosystem, $50 \mu \mathrm{L}$ in $1 \mathrm{cc}$ special dissolved buffer) as one drop on slides in the moist and preferably warm medium for better reaction in a dark environment for $30 \mathrm{~min}$, washing with distilled water, pouring hematoxylin (Gill) as one drop for $1 \mathrm{~min}$, washing with distilled water, immersing the slides in absolute alcohol as one-shot movement, drying slides, placing in three clean xylol containers, mounting and labelling the slides, and observing under microscope. After IHC staining, regarding the level of expression of estrogen receptor and progesterone receptors, 5 and 3 slides had not been stained well, respectively, and thus could not be evaluated. Considering investigation of the level of estrogen and progesterone receptors, 49 and 51 patients whose relevant information was available were used, respectively.

2.2. Statistical Analysis. The level of expression of estrogen receptor was categorized into three groups: less than $10 \%$, $10-50 \%$, and more than $50 \%$ [8]. Once collected, the data were introduced into SPSS 22 and analyzed using Chisquare test (Fisher exact test) at $5 \%$ significance level. 
TABLE 1: Distribution of clinical and pathological variable in patients suffering from colorectal cancer.

\begin{tabular}{|c|c|c|c|}
\hline Characteristic & $N(\%)$ & Characteristic & $N(\%)$ \\
\hline Gender (male) & $35(64.8)$ & Using alcohol & $2(3.7)$ \\
\hline Age $(\geq 50)$ years & $39(72.2)$ & History of inflammatory bowel diseases & $9(16.7)$ \\
\hline Using cigarette & $18(33.3)$ & Familial history of colorectal cancer & $7(13)$ \\
\hline Using opium & $32(59.3)$ & \multirow{2}{*}{ History of urethrosigmoidostomy } & \multirow{2}{*}{$2(3.7)$} \\
\hline Using hookah & $12(22.2)$ & & \\
\hline \multicolumn{4}{|c|}{ Colorectal cancer localization } \\
\hline Cecum & & & $2(5.6)$ \\
\hline Ascending colon & & & $6(11.1)$ \\
\hline Sigmoid colon & & & $3(5.6)$ \\
\hline Colon transverse & & & $2(3.7)$ \\
\hline Splenic flexure & & & $3(5.6)$ \\
\hline Descending colon & & & $7(13)$ \\
\hline Sigmoid & & & $14(25.9)$ \\
\hline Rectosigmoid & & & $4(7.4)$ \\
\hline Rectum & & & $12(22.2)$ \\
\hline
\end{tabular}

\section{Results}

3.1. Distribution of Clinical and Pathological Variable in Patients Suffering from Colorectal Cancer. Out of the 54 patients studied, $35(64.8 \%)$ were male, and the rest were female. The mean age of the patients was $62.28 \pm 14.03$ years (30-86 years). Prevalence of cigarette smoking, waterpipe smoking, drugs of abuse, and alcohol consumption in the patients was reported $33.3 \%, 22.2 \%, 59.3 \%$, and $3.7 \%$, respectively. Further, $16.7 \%(n=9)$ of the patients had inflammatory bowel disease; $13 \%(n=7)$ had familial history of colorectal cancer, and only $2(3.7 \%)$ had a history of radiation to the hip. None of the patients had Lynch syndrome, genetic diseases such as FAP, or history of proctosigmoidoscopy (Table 1).

3.2. Distribution of Clinical and Pathological Covariates in According to ER $\beta$ and PR Expression. The findings indicated that there was a significant relationship between age of the patients suffering colorectal cancer and the level of expression of estrogen plus progesterone receptors $(P=0.001)$. The level of expression of estrogen receptor in most of the patients younger than 50 years was $10-50 \%$, and in most patients 50 years of age and older than 50 years was less than $10 \%$. In addition, most of the patients younger than 50 years showed progesterone receptor expression of above $50 \%$, while the level of expression of progesterone receptor in most patients older than 50 years was less than $10 \%$.

The findings also showed that there was a significant relationship between the level of expression of estrogen and progesterone receptors and consuming drugs of abuse among the colorectal cancer patients $(P=0.001)$. Out of 29 patients $(59.2 \%)$ consuming drugs of abuse, $25(86.2 \%)$ had low level of receptor expression and $4(13.8 \%)$ had moderate levels of receptor expression. The level of expression of progesterone receptors was as follows: $17(87.1 \%)$ as low, 3 $(9.7 \%)$ as moderate, and $1(3.2 \%)$ as high.
Based on the findings of the present study, there was a significant relationship between the level of expression of estrogen plus progesterone receptors and grade of cancer $(P=0.001)$; the patients in more advanced grades of colorectal cancer showed lower level of expression of estrogen and progesterone receptors. In addition, the findings showed that there was no significant relationship between gender, cigarette smoking, waterpipe smoking, and having inflammatory bowel disease and level of expression of estrogen and progesterone receptors in patients with colorectal cancer $(P>0.05)$ (Table 2).

\section{Discussion}

Steroid hormones play important physiological roles in the reproductive system, bone, cardiovascular system, and brain functioning [9-11]. Estrogen has oncogenic and tumorstimulating roles in different tissues such as the breast, ovaries, uterus, prostate, and colon [12-15]. It has recently been shown that estrogen and progesterone receptors are expressed in normal mucus tissue, malignant colon tissue, and rectal tissue. In line with advances in diagnostic techniques, the role of estrogen and progesterone in tumorigenesis and incidence of colon cancer became more evident [16]. Nevertheless, some studies have shown low expression of progesterone in colon tumors and its absence of carcinogenic effects in animal studies [17]. The present study was performed to investigate the factors associated with the level of expression of estrogen and progesterone receptors in patients suffering from colorectal cancer. Based on results, there was a significant relationship between the age of patients with colorectal and the level of expression of estrogen plus progesterone receptors; the level of expression of estrogen receptor was $10-50 \%$ in most patients younger than 50 years and less than $10 \%$ in most patients 50 years of age and above. In addition, most patients younger than 50 years showed progesterone receptor expression above $50 \%$, while the level of expression 
TABLE 2: Distribution of clinical and pathological covariates in according to ER $\beta$ and PR expression.

\begin{tabular}{|c|c|c|c|c|c|c|c|c|}
\hline Characteristic & Low $N(\%)$ & $\begin{array}{l}\text { ER } \beta \text { expression } \\
\text { Moderate } N(\%)\end{array}$ & High $N(\%)$ & $P$ value & Low $N(\%)$ & $\begin{array}{c}\text { PR expression } \\
\text { Moderate } N(\%)\end{array}$ & High $N(\%)$ & $P$ value \\
\hline \multicolumn{9}{|l|}{ Gender } \\
\hline Male & $22(68.8)$ & $8(25)$ & $2(6.3)$ & 0.499 & $23(67.6)$ & $7(20.6)$ & $4(11.8)$ & 0.774 \\
\hline Female & $9(52.9)$ & $7(41.2)$ & $1(5.9)$ & & $10(58.8)$ & $5(29.4)$ & $2(11.8)$ & \\
\hline \multicolumn{9}{|l|}{ Age (years) } \\
\hline$<50$ & $4(28.6)$ & $7(50)$ & $3(21.4)$ & 0.001 & $4(26.7)$ & $5(33.3)$ & $6(40)$ & 0.001 \\
\hline$\geq 50$ & $27(77.1)$ & $8(22.9)$ & $0(0)$ & & $29(80.6)$ & $7(19.4)$ & $0(0)$ & \\
\hline \multicolumn{9}{|l|}{ Using cigarette } \\
\hline Yes & $11(68.8)$ & $5(31.2)$ & $0(0)$ & 0.456 & $12(66.7)$ & $5(27.8)$ & $1(5.6)$ & 0.565 \\
\hline No & $20(60.6)$ & $10(30.3)$ & $3(9.1)$ & & $21(63.6)$ & $7(21.2)$ & $5(15.2)$ & \\
\hline \multicolumn{9}{|l|}{ Using opium } \\
\hline Yes & $25(86.2)$ & $4(13.8)$ & $0(0)$ & 0.001 & $27(87.1)$ & $3(9.7)$ & $1(3.2)$ & 0.001 \\
\hline No & $6(30)$ & $11(55)$ & $3(15)$ & & $6(30)$ & $9(45)$ & $5(25)$ & \\
\hline \multicolumn{9}{|l|}{ Using hookah } \\
\hline Yes & $8(72.7)$ & $2(18.2)$ & $1(9.1)$ & 0.571 & $8(66.6)$ & $2(16.7)$ & $2(16.7)$ & 0.725 \\
\hline No & $23(60.5)$ & $13(34.2)$ & $2(5.3)$ & & $25(64.1)$ & $10(25.6)$ & $4(10.3)$ & \\
\hline \multicolumn{9}{|c|}{ History of inflammatory bowel diseases } \\
\hline Yes & $4(44.4)$ & $4(44.4)$ & $1(11.2)$ & 0.364 & $4(44.5)$ & $2(22.2)$ & $3(33.3)$ & 0.091 \\
\hline No & $27(67.5)$ & $11(27.5)$ & $2(5)$ & & $29(69)$ & $10(23.8)$ & $3(7.1)$ & \\
\hline \multicolumn{9}{|c|}{ Familial history of colorectal cancer } \\
\hline Yes & $1(14.3)$ & $4(57.1)$ & $2(28.6)$ & 0.004 & $1(14.3)$ & $3(42.9)$ & $3(42.9)$ & 0.004 \\
\hline No & $30(71.4)$ & $11(26.2)$ & $1(2.4)$ & & $32(72.7)$ & $9(20.5)$ & $3(6.8)$ & \\
\hline \multicolumn{9}{|l|}{ Grade } \\
\hline I & $0(0)$ & $7(77.8)$ & $2(22.2)$ & 0.001 & $0(0)$ & $5(50)$ & $5(50)$ & 0.001 \\
\hline II & $8(53.3)$ & $6(40)$ & $5(50)$ & & $9(56.2)$ & $6(37.5)$ & $1(4)$ & \\
\hline III & $23(92)$ & $2(8)$ & $0(0)$ & & $24(96)$ & $1(6.3)$ & $0(0)$ & \\
\hline
\end{tabular}

of progesterone receptor in most patients above 50 years was less than $10 \%$. In the study by $\mathrm{Oh}$ et al., to examine the risk factors of breast cancer with regard to estrogen receptor, progesterone receptor, insulin-like growth factor, and expression of Ki67 in normal breast tissue in 2017, the median level of estrogen expression was significantly higher in older women (equal to or greater than 50 years) than among those younger than 50 years of age, but the expression of progesterone had no significant relationship with age [18]. Some studies have also indicated that in populations in which most or all women were in postmenopausal period, 3-7\% positive estrogen cells and $12-29 \%$ positive progesterone cells were observed in the normal epithelium of the breast of women who did not have breast cancer [19-23]. In the study by Zhou et al., there was a correlation between the expression of estrogen in tumor tissues and age of patients, while there was no correlation between the expression of progesterone and age of patients [24].

The findings also showed that there was a significant relationship between the level of expression of estrogen as well as progesterone receptors and consuming drugs of abuse in patients suffering from colorectal cancer. In spite of many observational experimental studies, the role of prescribing opium substances on the immune system of human body and progression of cancers is unclear. One of the major limitations in investigating clinical benefits is the biological diversity of tumors. Most studies performed on the effect of opium drugs on the course of cancers have examined digestive system, lung, prostate, and breast cancers; according to investigations by the researchers of this paper, no studies have been done on the effect of opium substances on the course of cancers and expression of steroid hormones $[25,26]$.

Based on the findings of the present study, there was a significant relationship between the level of expression of estrogen plus progesterone receptors and grade of cancer; in patients with higher grades of colorectal cancer, the level of expression of estrogen as well as progesterone was lower. Nevertheless, there was no significant relationship between gender, cigarette smoking, waterpipe smoking, and having inflammatory bowel disease and the level of expression of estrogen plus progesterone receptors in patients suffering from colorectal cancer. In the study by Wenxi et al., who examined immunohistological expression of estrogen in 65 patients suffering from colorectal cancer, it was found that the level of positive expression of estrogen was significantly higher in tumor tissues compared to normal tissue. Also, expression of estrogen was independent of age and gender of patients, as well as the size, site, and grade of Ducke tumors [27]. Some studies have also reported that the immunohistological expression of estrogen in colorectal cancer is 
not associated with age of patient, gender, position of tumor, pathological type, histological type, or grade of disease [28, 29]. Although Zhou et al. showed that the quantitative levels of estrogen and progesterone expression were higher in cancerous tissues compared to normal tissues, and there was a positive correlation between the level of expression of estrogen as well as progesterone in tumor tissues; there was no correlation between the expression of estrogen or progesterone and gender, grade, position, and size of tumor [24]. In the study by Zavarhei et al., the expression of progesterone had a significant correlation with the size and grade of tumor [30]. In line with the results of the present study, in the study by Azizun-Nisa et al. conducted on patients suffering from breast cancer, it was found that higher grades of breast cancer disease were associated with lower level of expression of estrogen and progesterone, and this difference was significant [31]. Nguyen- $\mathrm{Vu}$ et al., examining the association between beta-estrogen receptor and colorectal cancer, concluded that the beta-estrogen receptor reduces metastasis of colorectal cancer through a new mechanism called miR205-PROX1. This study showed that oncogenic prosperhomebox 1 (PROX1) is a potential target of Rim-205. Also, $\operatorname{Er} \beta$ and miR-205 would reduce colorectal cancer compared to nontumorous colon, whole PROX1 level increases. This was in line with the results of the present study regarding the association between estrogen receptor and decreased colorectal cancer [32].

In this study by Botteri et al. conducted on patients with colorectal cancer, it was observed that hormone therapy was associated with decreased risk of colorectal cancer especially in the advanced stages of the disease [33]. Based on the results of various studies, beta-estrogen receptor $(\mathrm{ER} \beta)$ regulates DNA repair, increases apoptosis, and reduces cell replication. Thus, activation of ER $\beta$ can shrink the tumor and prevent its progression $[34,35]$.

\section{Conclusion}

Accordingly, relying on the results of the present study as well as other pieces of research in this regard, it can be stated that the expression of estrogen and progesterone receptors is associated with the progression and prognosis of the disease. Possibly, through hormone therapy, one could take a step in reducing the progression of colorectal cancer and even in treating it. It is also suggested to conduct studies with larger sample size in this regard.

\section{Data Availability}

The dataset collected and analysed during the current study are available from the corresponding author on reasonable request.

\section{Conflicts of Interest}

The authors declare that they have no competing interest.

\section{Acknowledgments}

The authors would like to thank Birjand University of Medical Sciences, Birjand, Iran, and also, Clinical Research Development Unit of Razi Hospital for consultation/editor$\mathrm{ial} /$ statistical assistance. This study was funded and supported by the Birjand Universities of Medical Sciences.

\section{References}

[1] S. Sabouri, H. Esmaily, S. Shahid Sales, and M. Emadi, "Determining related factors to survival of colorectal cancer patients using cox regression," Medical journal of mashhad university of medical sciences, vol. 61, no. 4, pp. 1083-1092, 2018.

[2] M. P. Curado, B. Edwards, H. R. Shin et al., Cancer Incidence in Five Continents, Volume IX: IARC Press, International Agency for Research on Cancer, 2007.

[3] M. Arnold, M. S. Sierra, M. Laversanne, I. Soerjomataram, A. Jemal, and F. Bray, "Global patterns and trends in colorectal cancer incidence and mortality," Gut, vol. 66, no. 4, pp. 683691, 2017.

[4] A. Ganji, M. Safavi, S. Nouraie et al., "Digestive and liver diseases statistics in several referral centers in Tehran, 20002004," Govaresh, vol. 11, no. 1, pp. 33-38, 2006.

[5] M. A. Pourhoseingholi, Z. Fazeli, F. S. Fazeli-Bavandpour, and A. Abadi, "Study of mortality trends of colorectal cancer in Iran between 1995 and 2004," Medical Science Journal of Islamic Azad Univesity-Tehran Medical Branch, vol. 23, no. 4, pp. 16-20, 2014.

[6] C. V. Sasso, F. E. Santiano, F. Campo Verde Arboccó et al., "Estradiol and progesterone regulate proliferation and apoptosis in colon cancer," Endocrine connections, vol. 8, no. 3, pp. 217-229, 2019.

[7] Y. Tanaka, K. Kato, R. Mibu et al., "Medroxyprogesterone acetate inhibits proliferation of colon cancer cell lines by modulating cell cycle-related protein expression," Menopause, vol. 15, no. 3, pp. 442-453, 2008.

[8] A. Rudolph, C. Toth, M. Hoffmeister et al., "Expression of oestrogen receptor $\beta_{-}$and prognosis of colorectal cancer," British journal of cancer, vol. 107, no. 5, pp. 831-839, 2012.

[9] K. A. Burns and K. S. Korach, "Estrogen receptors and human disease: an update," Archives of Toxicology, vol. 86, no. 10, pp. 1491-1504, 2012.

[10] J.-F. Arnal, M.-C. Valéra, B. Payrastre, F. Lenfant, and P. Gourdy, "Structure-function relationship of estrogen receptors in cardiovascular pathophysiological models," Thrombosis Research, vol. 130, pp. S7-S11, 2012.

[11] B. J. Deroo and K. S. Korach, "Estrogen receptors and human disease," The Journal of clinical investigation, vol. 116, no. 3, pp. 561-570, 2006.

[12] V. C. Jordan, "Chemoprevention of breast cancer with selective oestrogen-receptor modulators," Nature Reviews Cancer, vol. 7, no. 1, pp. 46-53, 2007.

[13] V. Syed, G. Ulinski, S. C. Mok, G. K. Yiu, and S.-M. Ho, "Expression of gonadotropin receptor and growth responses to key reproductive hormones in normal and malignant human ovarian surface epithelial cells," Cancer research, vol. 61, no. 18, pp. 6768-6776, 2001.

[14] G. F. Zannoni, G. Monterossi, I. de Stefano et al., "The expression ratios of estrogen receptor $\alpha(\mathrm{ER} \alpha)$ to estrogen receptor $\beta 1(\mathrm{ER} \beta 1)$ and $\mathrm{ER} \alpha$ to $\mathrm{ER} \beta 2$ identify poor clinical outcome 
in endometrioid endometrial cancer," Human pathology, vol. 44, no. 6, pp. 1047-1054, 2013.

[15] P. L. Härkönen and S. I. Mäkelä, "Role of estrogens in development of prostate cancer," The Journal of steroid biochemistry and molecular biology, vol. 92, no. 4, pp. 297-305, 2004.

[16] B. Zhu and C. M. Zhang, "Progress of relationship between ER, PR and prognosis of colorectal cancer," Medical Recapitulate, vol. 21, 2008.

[17] J. Heijmans, V. Muncan, R. J. Jacobs et al., "Intestinal tumorigenesis is not affected by progesterone signaling in rodent models," PLoS One, vol. 6, no. 7, article e22620, 2011.

[18] H. Oh, A. H. Eliassen, A. H. Beck et al., "Breast cancer risk factors in relation to estrogen receptor, progesterone receptor, insulin-like growth factor-1 receptor, and Ki67 expression in normal breast tissue," NPJ breast cancer, vol. 3, no. 1, pp. 18, 2017.

[19] G. Williams, E. Anderson, A. Howell et al., "Oral contraceptive (OCP) use increases proliferation and decreases oestrogen receptor content of epithelial cells in the normal human breast," International journal of cancer, vol. 48, no. 2, pp. 206-210, 1991.

[20] J. D. Jacquemier, J. Hassoun, M. Torrente, and P.-M. Martin, "Distribution of estrogen and progesterone receptors in healthy tissue adjacent to breast lesions at various stages-immunohistochemical study of 107 cases," Breast cancer research and treatment, vol. 15, no. 2, pp. 109-117, 1990.

[21] S. A. Khan, M. A. Rogers, K. K. Khurana, M. M. Meguid, and P. J. Numann, "Estrogen receptor expression in benign breast epithelium and breast cancer risk," JNCI: Journal of the National Cancer Institute, vol. 90, no. 1, pp. 37-42, 1998.

[22] O. Petersen, P. Høyer, and B. Van Deurs, "Frequency and distribution of estrogen receptor-positive cells in normal, nonlactating human breast tissue," Cancer research, vol. 47, no. 21, pp. 5748-5751, 1987.

[23] B. S. Shoker, C. Jarvis, R. B. Clarke et al., "Estrogen receptorpositive proliferating cells in the normal and precancerous breast," The American journal of pathology, vol. 155, no. 6, pp. 1811-1815, 1999.

[24] Z. W. Zhou, D.-S. Wan, G.-Q. Wang et al., "Expression of estrogen receptor and progesterone receptor in colorectal cancer: a quantitative study," Chinese journal of cancer, vol. 23, no. 7, pp. 851-854, 2004.

[25] G. Amodeo, D. Bugada, S. Franchi et al., "Immune function after major surgical interventions: the effect of postoperative pain treatment," Journal of pain research, vol. Volume 11, pp. 1297-1305, 2018.

[26] T. Kavanagh and D. J. Buggy, "Can anaesthetic technique effect postoperative outcome?," Current Opinion in Anesthesiology, vol. 25, no. 2, pp. 185-198, 2012.

[27] W. Wenxi, S. Lizong, and Y. Dongming, "Expression of estrogen receptor and $\mathrm{P}$ glycoprotein in primary colorectal carcinoma," The Practical Journal of Cancer, vol. 3, pp. 20-28, 1999.

[28] Z. Qin, D. Wan, J. Lian, H. Lin, and J. Hou, "Expression of $\mathrm{nm} 23$ protein and estrogen receptor and prognosis of colorectal cancers," Zhonghua wai ke za zhi [Chinese Journal of Surgery], vol. 38, no. 7, pp. 514-516, 2000.

[29] Q. Zike, W. Desen, L. Jun-yan, L. Han-liang, and H. Jing-hui, "Expression and prognostic values of p21 protein and estrogen receptor in colorectal cancers," Chinese Journal of Cancer, vol. 20, pp. 5-9, 2001.

[30] M. D. Zavarhei, S. A. Bidgoli, M. M. Ziyarani, M. Shariatpanahi, and F. A. Ardalan, "Progesterone receptor positive colorectal tumors have lower thymidine phosphorylase expression: an immunohistochemical study," Pakistan journal of biological sciences: PJBS, vol. 10, no. 24, pp. 4485-4489, 2007.

[31] B. Y. Azizun-Nisa, F. Raza, and N. Kayani, "Comparison of ER, $\mathrm{PR}$ and HER-2/neu (C-erb B 2) reactivity pattern with histologic grade, tumor size and lymph node status in breast cancer," Asian Pacific Journal of Cancer Prevention, vol. 9, no. 4, pp. 553-556, 2008.

[32] T. Nguyen-Vu, J. Wang, F. Mesmar et al., "Estrogen receptor beta reduces colon cancer metastasis through a novel miR205-PROX1 mechanism," Oncotarget, vol. 7, no. 27, pp. 42159-42171, 2016.

[33] E. Botteri, N. C. Støer, S. Sakshaug et al., "Menopausal hormone therapy and colorectal cancer: a linkage between nationwide registries in Norway," BMJ Open, vol. 7, no. 11, article e017639, 2017.

[34] J. Hartman, K. Edvardsson, K. Lindberg et al., "Tumor repressive functions of estrogen receptor $\beta$ in SW480 colon cancer cells," Cancer research, vol. 69, no. 15, pp. 6100-6106, 2009.

[35] H. Hsu, S. Cheng, C. Wu et al., "Apoptotic effects of overexpressed estrogen receptor-beta on LoVo colon cancer cell is mediated by 53 signalings in a ligand-dependent manner," Chinese Journal of Physiology, vol. 49, no. 2, p. 110, 2006. 